\title{
Potential of Phaeodactylum tricornutum for Biodiesel Production under Natural Conditions in Chile
}

\author{
Monique Branco-Vieira 1,2,3,*, Sergio San Martin ${ }^{4}$, Cristian Agurto ${ }^{4}$, Marco Aurélio dos Santos ${ }^{1}$, \\ Marcos A. V. Freitas ${ }^{1}$, Teresa M. Mata ${ }^{3}$, António A. Martins ${ }^{3}$ and Nídia S. Caetano ${ }^{2,3}$ (iD \\ 1 Energy Planning Program, Federal University of Rio de Janeiro, 21941-914 Rio de Janeiro, Brazil; \\ aurelio@ppe.ufrj.br (M.A.d.S.); mfreitas@ppe.ufrj.br (M.A.V.F.) \\ 2 CIETI, School of Engineering (ISEP), Polytechnic Institute of Porto (IPP), 4200-072 Porto, Portugal; \\ nsc@isep.ipp.pt \\ 3 LEPABE, Faculty of Engineering, University of Porto, 4200-465 Porto, Portugal; tmata@fe.up.pt (T.M.M.); \\ antonioareosamartins@gmail.com (A.A.M.) \\ 4 GIBMAR, Biotechnology Centre, Concepción University, 4070386 Concepción, Chile; \\ sergio.sanmartin.p@gmail.com (S.S.M.); cagurto@udec.cl (C.A.) \\ * Correspondence: monique.branco@fe.up.pt
}

Received: 10 November 2017; Accepted: 25 December 2017; Published: 28 December 2017

\begin{abstract}
Diatoms are very diverse and highly productive organisms, found in a wide variety of environments. This study aims to analyze the growth and lipid composition of Phaeodactylum tricornutum, cultured in an outdoor pilot-scale bubble column photobioreactor under natural conditions in Chile for biodiesel production. Results showed that P. tricornutum cultures reached their highest biomass concentration $\left(0.96 \pm 0.04 \mathrm{~kg} \mathrm{~m}^{-3}\right)$ after 14 days of culturing, at the stationary phase, with a volumetric productivity of $0.13 \mathrm{~kg} \mathrm{~m}^{-3} \mathrm{~d}^{-1}$. Biomass samples showed a total lipid content of $9.08 \pm 0.38 \mathrm{wt} \%$. The fatty acid methyl ester analysis revealed a composition of $24.39 \% \mathrm{C} 16-\mathrm{C} 18$ fatty acids, $42.34 \%$ saturated fatty acids, $21.91 \%$ monounsaturated fatty acids and $31.41 \%$ polyunsaturated fatty acids. These findings suggest that $P$. tricornutum oil can be used as an alternative raw material for the production of biodiesel capable of meeting international quality standards.
\end{abstract}

Keywords: bubble column photobioreactor; lipids; microalgae; natural culture conditions; outdoor culture

\section{Introduction}

The production of biofuels offers new opportunities to mitigate climate change and promote energy security. Furthermore, the complementation of fossil fuels, used for many decades as a primary energy source, leads to a circular economy approach by closing the carbon cycle [1]. In this context, microalgae have attracted significant interest as feedstock for different types of renewable fuels such as biodiesel, methane, hydrogen and ethanol, among others [2].

Microalgae photosynthetic metabolism produces valuable compounds using solar energy, water, carbon dioxide and other available compounds. Through this metabolic process, they are capable of generating raw materials to use in biofuels, food and feed production [3]. Their high areal productivity and lipid content offer several advantages over traditional crops. Also, the possibility of using non-arable land and non-potable water (such as sea or wastewater), reduces the competition with food crops and secures sustainability [4]. Moreover, the production of microalgae biodiesel can be associated with other co-products, increasing their economic feasibility and sustainability [5]. Also, it is possible to effectively combine microalgae cultivation with wastewater treatment, reducing operating costs and simultaneously allowing potential waste valorization [6].

Among eukaryotic phytoplankton, diatoms (Bacillariophyceae) represent the largest population of microalgae in the ocean [7]. They are responsible for nearly $40 \%$ of marine primary productivity [8] 
and represent the richest group of algae species, with approximately 100,000 known species in both marine and freshwater environments. However, only 12,000 of them have been described so far [9]. Despite their abundance, diversity and simplicity to cultivate, only a few of them have been cultured for biotechnology or production purposes [10].

The marine diatom Phaeodactylum tricornutum is an ecologically significant, poly-morphological and unicellular microalga. It is well-known and modelled for studying the physiology, biochemistry and genomics of diatoms, whose complete genome information is already available [11]. This species can accumulate diverse metabolites such as carotenoids, proteins, carbohydrates, silica and polyunsaturated fatty acids (PUFA), some of them largely used for aquaculture, animal feed and human consumption $[2,3,10]$. In particular, it is a potential source of eicosapentaenoic acid, 20:5n3 (EPA), an essential PUFA, and fucoxanthin, a major pigment in diatoms and one of the most abundant carotenoids in nature, especially in marine environments, which are known to be essential nutrients for animals [12].

Recently, P. tricornutum has been considered as a potential candidate for biodiesel production due to its high growth rate under optimum conditions and its lipid content, ranging from 20 to 30 dry wt \% under photoautotrophic conditions [7]. Moreover, this marine diatom grows in saline water and does not compete with freshwater sources, which makes it more commercially attractive. Its components, fucoxanthin and PUFA, are regarded as economically valuable co-products that can be extracted to effectively offset the costs of its cultivation for biodiesel production [12].

The success of mass culture of Phaeodactylum to obtain highly valuable products, such as PUFA and lipids for biodiesel production requires the optimization of growth conditions, particularly temperature, light and nitrogen deficiency [7]. These factors are strongly influenced by the type of reactor used for this process. Nowadays, large-scale production of microalgae can be done both in open ponds and photobioreactors (PBR), being the production costs considerably lower in the first.

Concerning the culture of some Phaeodactylum species, it is mandatory the use of closed PBR, as they require strict control of temperature in the range of $20-25^{\circ} \mathrm{C}$, which is difficult to maintain in open ponds [13]. PBRs for microalgae cultivation have a wide range of configurations, designed to obtain high biomass volume per unit, according to each culture purpose. Photobioreactors are usually structured in flat plates, alpha-helix, horizontal tubular, concentric air-lift, helical tubular, air lift flat plates, semispherical and bubble column designs [14,15].

Bubble columns are used as an alternative to conventional PBR designs due to their low-cost production and operational simplicity. Furthermore, this type of PBR is compact and effective for producing large quantities of biomass and scaling up lab and pilot-scale culture into higher volumes [16]. However, there is scarce information regarding the characterization of microalgae grown in outdoor pilot-scale bubble columns, operated under natural solar irradiance and temperature, capable of increasing the efficiency and sustainability of the process [16-19]. Studies about this issue are needed for establishing the foundations of more efficient large-scale microalgae cultivation using this system [20].

Phaeodactylum tricornutum has been cultured for its long-chain PUFA. In general, nutrient limitation, in particular nitrogen, is the most effective method for improving microalgal lipid content, although the response is species-specific [21]. Several studies of the influence of culture conditions on lipid production have been performed, both for laboratory [12,13] and outdoor conditions $[8,22]$. The general conclusion arising from these studies is that the biochemical composition of microalgae and their growth rate are determined by environmental factors, such as temperature, light availability, nutrients and salinity. In addition to environmental factors, the growth phase or culture time also have significant effect on the biochemical composition of microalgal cells [12]. However, no definitive conclusions on the most adequate conditions to obtain higher quantities of certain compounds can be obtained from the literature. 
In this study the culture growth and lipid composition of $P$. tricornutum cultivated in outdoor pilot-scale bubble columns PBR is analyzed. The experiments were performed in Concepción, Chile, which enjoys a temperate Mediterranean, bordering on Oceanic climate.

\section{Materials and Methods}

\subsection{Culture Conditions}

The cultures of the diatom P. tricornutum Bohlin (originating from Cañar Blanco, La Serena, IV Region, Chile), initially stored at the laboratory's culture collection, were maintained by sub-cultivation in $250 \mathrm{~mL}$ Erlenmeyer flasks with $100 \mathrm{~mL}$ culture medium, aerated with atmospheric air supplied by an air blower with a flow rate of $120 \mathrm{~L} / \mathrm{min}, 0.18$ bar (LA-120A, Nitto Kohki Co. Ltd., Tokyo, Japan) at $23 \pm 1{ }^{\circ} \mathrm{C}$ under artificial light with $200 \mu \mathrm{mol}$ photons $\mathrm{m}^{-2} \mathrm{~s}^{-1}$ in 16:8 (light:dark) cycles. The Walne culture medium [23], supplemented with $0.017 \mathrm{~g} \mathrm{~L}^{-1}$ of silicate, was prepared with natural seawater, filtered and autoclaved for $45 \mathrm{~min}$ at $20 \mathrm{psi}$ and $121{ }^{\circ} \mathrm{C}$. After 7 days of sub-cultivation the cultures were transferred into $1 \mathrm{~L}$ Erlenmeyer flasks under the same conditions, until the exponential growth phase was observed. The cultures were scaled-up into $20 \mathrm{~L}$ plastic carboys containing sterile Walne medium and silicate, under the same conditions of sub-cultures for approximately 14 days.

\subsection{Outdoor PBR Culture Management}

Phaeodactylum tricornutum samples were batch cultured in $800 \mathrm{~L}$ bubble column PBR, in outdoor conditions in Concepción, Chile, from January to March 2016. The PBR used for outdoor P. tricornutum cultivation consisted of four parallel acrylic tubes, each one with a length of $1.40 \mathrm{~m}$ and $0.45 \mathrm{~m}$ wide, capable of containing a $200 \mathrm{~L}$ volume, placed vertically on a woody base. The base of the tubes was conical and composed of PVC tubes that allowed samples to be harvested at the end of the cultivation period. A plastic cover closed the upper end of the tubes. The area occupied by the PBR was $1.27 \mathrm{~m}^{2}$ (Figure 1).

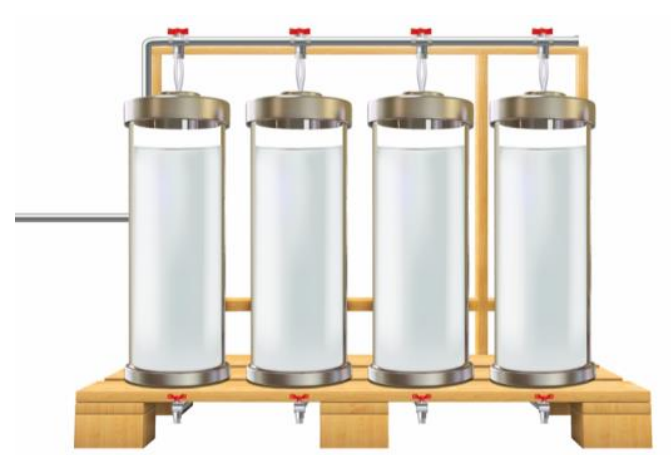

(a)

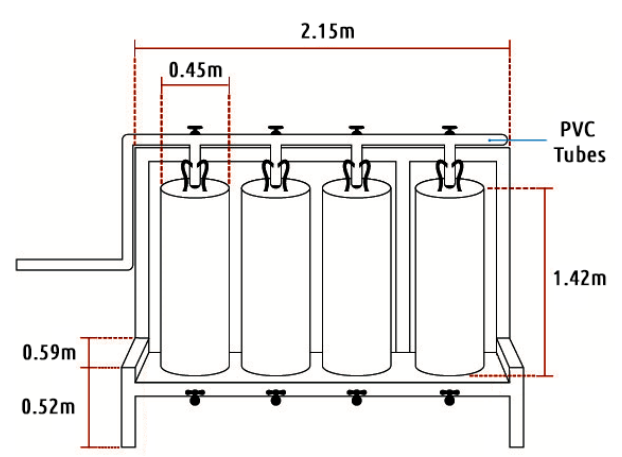

(b)

Figure 1. Bubble column PBR used for outdoor P. tricornutum cultivation. (a) Schematic illustration of the PBR; (b) Sketch map of the PBR front view containing all sizes.

The air bubbling within the culture was generated by an air blower with a flow rate of $200 \mathrm{~L}$ $\mathrm{min}^{-1}$, at 0.2 bar relative pressure (LAM-200, Nitto Kohki Co. Ltd., Tokyo, Japan) connected to the tubes by PVC tubes coupled to the cultures by rubber hose/glass capillary system. The PBR was oriented in an East/West direction; the latitude and longitude of the site were $36^{\circ} 50^{\prime} 02.1^{\prime \prime} \mathrm{S}$ and $73^{\circ} 01^{\prime} 49.3^{\prime \prime} \mathrm{W}$, respectively.

Initially, the tubes were filled-up with $170 \mathrm{~L}$ of natural seawater. Sodium hypochlorite $(\mathrm{NaClO})$ $0.03 \mathrm{~g} \mathrm{~L}^{-1}$ was added to natural seawater as a disinfectant agent, maintaining air bubbling overnight. After $24 \mathrm{~h}$ of treatment, the $\mathrm{NaClO}$ was neutralized with $100 \mathrm{~mL}$ of $\mathrm{Na}_{2} \mathrm{~S}_{2} \mathrm{O}_{3} 50 \mathrm{~g} \mathrm{~L}^{-1}$. The natural 
seawater was enriched with a commercially modified Guillard's f/2 formulation [24] with silicate (Pentair, Aquatic Eco-Systems, Minneapolis, MN, USA). The 20 L plastic carboys containing P. tricornutum culture were utilized as inoculum for each $200 \mathrm{~L}$ column. The cultures were monitored every day until the stationary growth phase was reached using an YSI 556 Multi-Probe System (YSI Inc., Yellow Springs, OH, USA) that measures the salinity, dissolved oxygen, temperature, and $\mathrm{pH}$. The natural illumination was measured every minute by a photosynthetically active daily-averaged irradiance (PAR) sensor (QSPL-2100 Quantum Scalar Laboratory sensors, Biospherical Instruments Inc., San Diego, CA, USA).

Aliquots of $50 \mathrm{~mL}$ were sampled regularly from each culture and measured at $750 \mathrm{~nm}\left(\mathrm{OD}_{750}\right)$, $680 \mathrm{~nm}\left(\mathrm{OD}_{680}\right)$ and $550 \mathrm{~nm}\left(\mathrm{OD}_{550}\right)$ in a HALO DB-20 UV/VIS double beam spectrophotometer (Dynamica Scientific Ltd, Newport Pagnell, UK). Optical density at $\mathrm{OD}_{750}$ served as proxies of dry biomass, calculated with previously determined equations $M=0.89 \times \mathrm{OD}_{750}+0.38\left(\mathrm{R}^{2}=0.97\right.$, $M=$ biomass $\left(\mathrm{g} \mathrm{L}^{-1}\right)$.

The photoinhibition was calculated by the relative measurement of the quantity of chlorophyll per mass of biomass through the ratio of $\mathrm{OD}_{680} / \mathrm{OD}_{550}$, for monitoring the possible culture contamination by bacteria and other organisms. This measurement can also be used as an indication of cell bleaching due to photoinhibition [25]. Cellular light scattering is usually determined for measuring culture absorption at $550 \mathrm{~nm}$ because algae can hardly absorb light at such point, whereas at $680 \mathrm{~nm}$, the optical density corresponds to both scattering and light absorption of chlorophyll-a. For healthy cells, this ratio should be above 1.0 [26].

Growth dynamics of the microalgae was quantified by the growth rate and the progressive sum of daily growth rate. Growth rate was determined using Equation (1):

$$
\mu=\frac{\left[\ln \left(\frac{X_{2}}{X_{1}}\right) / \ln 2\right]}{\Delta t}
$$

where $\mu$ is the growth rate $\left(\right.$ day $\left.^{-1}\right), X$ is microalgae biomass concentration at different time points $\left(\mathrm{kg} \mathrm{m}^{-3}\right)$, and $\Delta t$ is the difference between two time points (day).

The progressive sum of daily growth rate $\left(\sum \mu\right)$ is determined by using Equation (2):

$$
\sum \mu=\mu_{(n-1)}+\mu_{(n+1)}
$$

where $\sum \mu$ is the cumulated growth rate $\left(\right.$ day $\left.^{-1}\right), \mu_{(n-1)}$ is the growth rate at time 1 , and $\mu_{(n+1)}$ is the growth rate at time 2 .

After 14 days of cultivation, the microalgae were harvested by overnight flocculation, using $0.5 \mathrm{M}$ $\mathrm{NaOH}$ at $\mathrm{pH} 10.40$, followed by biomass centrifugation at $4000 \mathrm{rpm}$ for $5 \mathrm{~min}$ (Rotofix 32A, Hettich Zentrifugen, Tuttlingen, Germany). Then, they were stored at $-20^{\circ} \mathrm{C}$ until lyophilized at $-70 \pm 2{ }^{\circ} \mathrm{C}$ for about $72 \mathrm{~h}$ (FDU-7008, Operon, Yangchon-eup, South Korea). The total dry biomass was measured using an analytical balance (ABJ 220-4M, Kern, Balingen, Germany) and stored at $-20{ }^{\circ} \mathrm{C}$ until the remaining biochemical analysis was done.

\subsection{Microalgae Lipid Analysis}

For lipid extraction and transesterification, the following methods were performed at room temperature and pressure: (1) Soxhlet extraction using hexane as solvent; (2) Bligh and Dyer [27] method as modified by Mata et al. [28]; (3) direct Bligh and Dyer extraction and transesterification of lipids.

\subsubsection{Lipid Extraction with Hexane}

Ten grams of dry algae were placed in a cellulose thimble $(25 \mathrm{~mm}$ I.D., $28 \mathrm{~mm}$ O.D., $100 \mathrm{~mm}$ length) inside a Soxhlet extractor, using hexane as solvent, without any pre-treatment. The extraction 
was done at $60{ }^{\circ} \mathrm{C}$ for $24 \mathrm{~h}$ using $250 \mathrm{~mL}$ of hexane. After the solvent was removed, the extracted lipid was gravimetrically quantified using an analytical balance (Kern ABJ 220-4M).

\subsubsection{Lipid Extraction with Methanol/Chloroform}

Lipids of P. tricornutum were quantified after extraction using the Bligh and Dyer [27] method as modified by Mata et al. [28]. Chloroform, methanol and distilled water were added in ratios of 1:2:0.8 $(v / v)$, respectively, into $300 \mathrm{mg}$ of dried biomass. The resulting mixture was sonicated for 30 min (Ultrasons 6L, Selecta, Barcelona, Spain). A second extraction step was then performed by adding the co-solvents at ratios of 2:2:1.8 $(v / v)$ of chloroform, methanol and distilled water respectively. The samples were sonicated for another $30 \mathrm{~min}$, and then centrifuged at $3000 \mathrm{rpm}$ for $15 \mathrm{~min}$ (4000R Benchtop Refrigerated Laboratory Centrifuge, Centurion Scientific Ltd, West Sussex, UK). After centrifugation and resting, the lower layer was carefully recovered and transferred into another pre-weighted glass tube using a syringe. After the chloroform evaporated at room temperature, the extracted lipids were gravimetrically weighted (Kern ALJ 220-4) in order to estimate the total lipid content.

\subsubsection{Direct Bligh and Dyer extraction and Transesterification of Lipids}

Samples were tested by the Bligh and Dyer [27] method after placing $100 \mathrm{mg}$ of lyophilized biomass in a glass vial with $3 \mathrm{~mL}$ of chloroform-methanol 2:1 $(v / v), 1 \mathrm{mg} \mathrm{mL}^{-1}$ Tricosanoic acid (C23:0) as lipid standard, and $0.5 \mathrm{mg} \mathrm{mL}^{-1}$ butylated hydroxytoluene (BHT). The mixture was then shaken overnight at room temperature. After extraction, the mixture was centrifuged at $5000 \mathrm{rpm}$ (Hettich Zentrifugen Rotofix 32A) for $5 \mathrm{~min}$ at room temperature. The mixture was transferred to another funnel to allow the separation of organic and aqueous layers. The bottom layer was then collected, and the solvent was evaporated using $\mathrm{N}_{2}$. After the solvent evaporated, $1.5 \mathrm{~mL}$ of $\mathrm{NaOH}$ was poured into the flask, and the extracted lipids were heated to $100{ }^{\circ} \mathrm{C}$ for $5 \mathrm{~min}$.

The transesterification process was carried out using $2 \mathrm{~mL}$ of $\mathrm{BF}_{3}$ in methanol $(2 \mathrm{wt} \%)$ at $100{ }^{\circ} \mathrm{C}$ for $30 \mathrm{~min}$ in order to determine fatty acid methyl ester (FAME) content. Then, $1 \mathrm{~mL}$ of isooctane was added after the mixture cooled, followed by shaking for $30 \mathrm{~s}$. After, five milliliters of saturated $\mathrm{NaCl}$ was added before centrifugation. The upper phase was carefully transferred to $2 \mathrm{~mL}$ amber vials and stored at $-20^{\circ} \mathrm{C}$.

\subsubsection{GC Analysis}

Transesterified products were analyzed by a gas chromatograph-mass spectrometer (GC 6000 Vega Series 2, model 6300-03b, Carlo Erba Instruments Ltd, Wigan, UK), equipped with a HP-FFAP cross-linked FFAP ( $25 \mathrm{~m}$ length, $0.32 \mathrm{~mm}$ diameter, $0.52 \mu \mathrm{m}$ film thickness) column. A solution of $1 \mathrm{mg} \mathrm{mL} \mathrm{mL}^{-1}$ of FAME mix (Food Industry FAME Mix, Restek, Bellefonte, PA, USA) was used as the internal standard for FAME analysis. Samples $(1 \mu \mathrm{L})$ were injected at an initial oven temperature of $100{ }^{\circ} \mathrm{C}$. After injection, the oven was heated at $100^{\circ} \mathrm{C} / 5 \mathrm{~min}$ to $240{ }^{\circ} \mathrm{C}$ at $4{ }^{\circ} \mathrm{C} / \mathrm{min}$ and held at final temperature for $20 \mathrm{~min}$. The carrier gas was nitrogen $\left(\mathrm{N}_{2}\right)$ at $100 \mathrm{kPa}$. The injector temperature was $225^{\circ} \mathrm{C}$, and FID detector temperature was set at $250^{\circ} \mathrm{C}$. The acquisition data were performed with the Autochro Data Module (Younglin Instrument, Anyang, South Korea), and the Autochro-3000 Software (Younglin Instrument, Anyang, South Korea). FAME in samples were identified by comparing the retention times (RT) and area (mVs) of FAME peaks with those of internal standards.

The percentage of each FAME present on the dry sample was calculated using Equation (3):

$$
\text { FAME yield }(\text { wt } \%)=\frac{\text { Crude lipid yield }(w t \%) \times \text { FAME content }(\%)}{100}
$$




\subsection{Statistical Analysis}

Statistical analyses between samples and replicas were determined using mean and standard deviation, using Excel and STATISTICA ${ }^{\circledR} 7.0$ software (StatSoft, Inc., Palo Alto, CA, USA, 2004).

\section{Results and Discussion}

\subsection{Biomass Production}

The objective of the culture system was to decrease costs and human intervention during the experimental period. Hence, the microalgae culture was performed with complete nutritional medium from the starting point, without further addition of nutrients.

The diatom P. tricornutum was grown in the commercial culture medium $\mathrm{f} / 2$. The culture was monitored daily by measuring biomass concentration, temperature, $\mathrm{pH}$, salinity and dissolved oxygen concentration. The highest biomass concentration obtained in the early stationary phase was $0.96 \pm 0.04 \mathrm{~kg} \mathrm{~m}^{-3}$ at day 14 of cultivation (Figure 2).

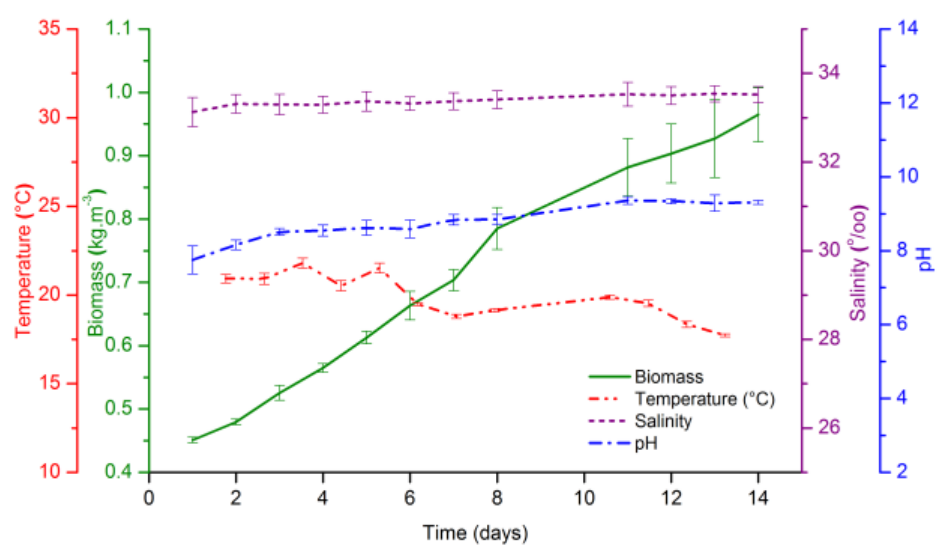

Figure 2. Variation of parameters for P. tricornutum batch culture during 14 days. Green line is the biomass concentration; red line is the culture temperature variation; purple line is the salinity of the culture and blue line is the culture's $\mathrm{pH}$ variation. Error bars are standard deviation.

The temperature varied from 17 to $21^{\circ} \mathrm{C}$, $\mathrm{pH}$ ranged from 7 to 9 and salinity remained almost constant during the entire cultivation period. On day 11, when temperature decreased, it was not possible to observe a significant variation in biomass concentration. At this point the culture reached the stationary phase and was harvested at day 14 (Figure 2).

The maximum volumetric productivity was $0.13 \mathrm{~kg} \mathrm{~m}^{-3} \mathrm{~d}^{-1}$ and the maximum areal productivity was $0.08 \mathrm{~kg} \mathrm{~m}^{-2} \mathrm{~d}^{-1}$ observed at day 8 of cultivation (Figure 3). Cumulated specific growth is shown in Figure 3, where it is possible to observe the variations that occurred in the microalgae growth. The stationary phase began after 8 days of cultivation, when the end of cellular divisions was observed and cumulated growth rate of about 0.97 day $^{-1}$ (Figure 3). Furthermore, the maximum growth rate of 0.17 day $^{-1}$ was also measured at day 8 of cultivation (Figure $4 \mathrm{~b}$ ). The range of maximum production and growth rates were observed at days 6 and 8 of cultivation. At this point, temperature started to decrease (see Figure 2) along with culture production which seemed to be strongly influenced by temperature variability (Figure 3). In fact, P. tricornutum showed substantial variability in biomass production during the year, showing higher productions in summer than in winter [29]. 


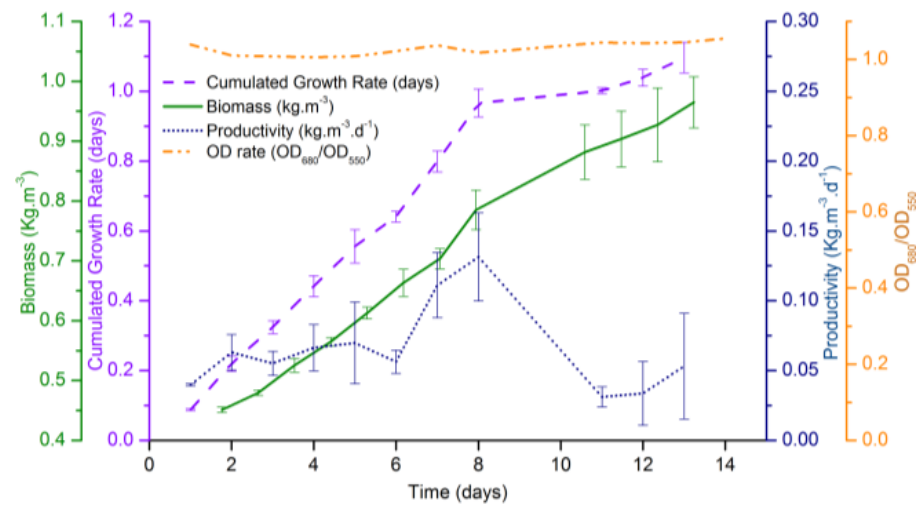

Figure 3. P. tricornutum biomass growth analysis during a batch culture regime. Green line is the biomass concentration; violet line is the cumulated growth rate; dark blue line is the culture productivity and orange line is the $\mathrm{OD}_{680} / \mathrm{OD}_{550}$ rate. Error bars are standard deviation.
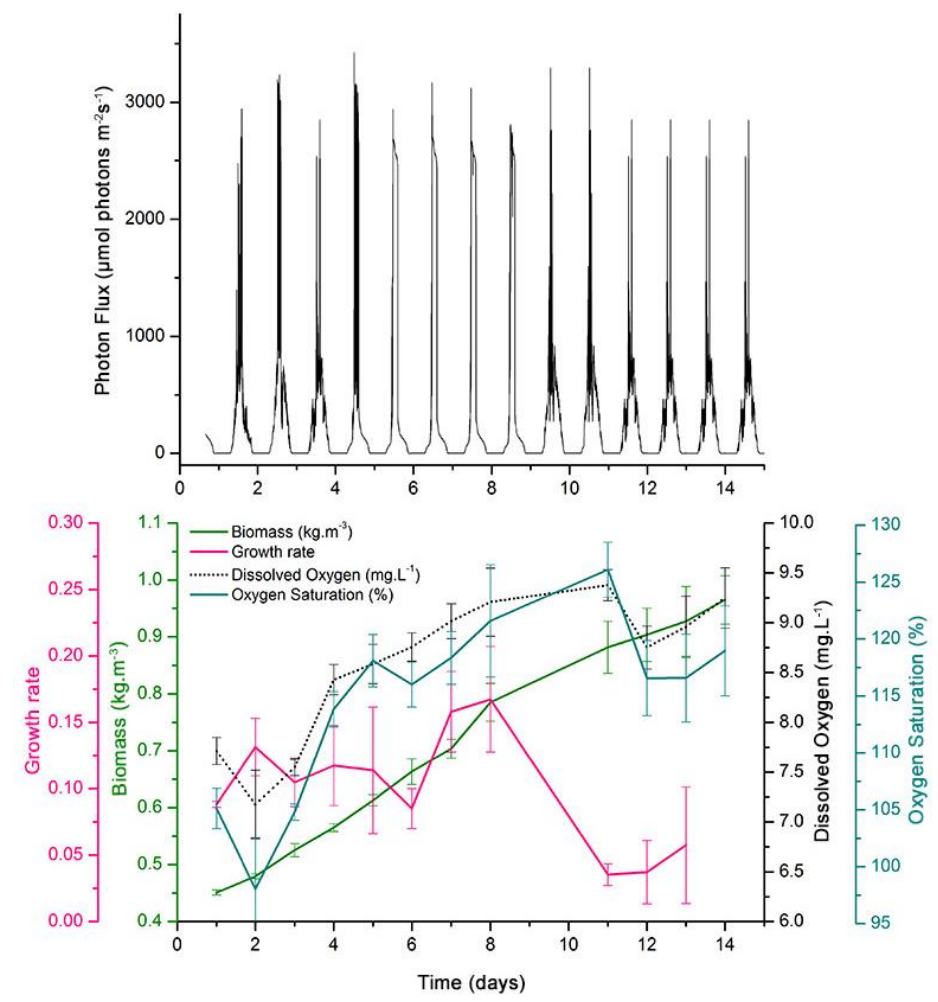

(a)

(b)

Figure 4. P. tricornutum biomass growth analyzed as a function of light intensity and dissolved oxygen variability during a batch culture regime. (a) PAR measured during the microalgae culture; (b) Biomass growth curve (green line), biomass growth rate (pink line), dissolved oxygen concentration in $\mathrm{mg} \mathrm{L}^{-1}$ (black line) and oxygen saturation (dark green line) obtained during cultivation time. Error bars are standard deviation.

Benavides et al. [8] have compared the biomass productivity of P. tricornutum grown outdoors at different biomass concentrations in open ponds and closed PBR. They have concluded that in general the productivity is higher in PBR because light is more efficiently used in this type of system. These authors have obtained optimal biomass concentrations of $0.6 \mathrm{~kg} \mathrm{~m}^{-3}$ and $1.0 \mathrm{~kg} \mathrm{~m}^{-3}$ in open ponds and PBR respectively. These concentrations are similar to the optimal biomass concentrations observed in this work. 
Usually, the biomass concentration and productivity of microalgae cultures are dependent on culture and climate conditions. In outdoor cultures, the PBR's location determines the values regarding temperature and solar irradiance, while dissolved oxygen and $\mathrm{pH}$ are dependent on PBR's design and operating conditions [29-31]. Indoor cultures, with smaller volumes and controlled parameters, have shown better performance, with higher production in comparison to the outdoor cultures with no controlled parameters $[19,20]$. However, this study showed higher average values of biomass productivity and concentration than some indoor experiments. For example, a study conducted by Song et al. [2] have achieved its highest biomass concentration $\left(0.5 \mathrm{~kg} \mathrm{~m}^{-3}\right)$, growth rate $\left(0.5 \mathrm{day}^{-1}\right)$ and biomass productivity $\left(0.23 \mathrm{~kg} \mathrm{~m}^{-3} \mathrm{~d}^{-1}\right)$ for P. tricornutum in an indoor $3 \mathrm{~L}$ bubble column PBR, under controlled light irradiance and temperature, batch regime and 8 days of culture.

Otherwise, production in other outdoor PBR designs usually reveals higher biomass concentration, but lower areal and volumetric productivities when compared with bubble column PBR. The volumetric and areal productivities in an outdoor horizontal tubular reactor in Spain during summer have shown about $1.9 \mathrm{~kg} \mathrm{~m}^{-3} \mathrm{~d}^{-1}$ and $0.32 \mathrm{~kg} \mathrm{~m}^{-3} \mathrm{~d}^{-1}$ respectively, along with a mass concentration of $P$. tricornutum equivalent to $2.3 \mathrm{~kg} \mathrm{~m}^{-3}$ [32]. Using an outdoor cylindrical helical tubular reactor, Hall et al. [33] have obtained a volumetric productivity and biomass concentration of $1.4 \mathrm{~kg} \mathrm{~m}^{-3} \mathrm{~d}^{-1}$ and $3.0 \mathrm{~kg} \mathrm{~m}^{-3}$, respectively, in a P. tricornutum culture in Spain. Sanchez et al. [34] have obtained a volumetric productivity of $P$. tricornutum equivalent to $1.48 \mathrm{~kg} \mathrm{~m}^{-3} \mathrm{~d}^{-1}$, cultured in an outdoor tubular reactor with a horizontal solar orientation.

Studies of P. tricornutum culture carried out by Sánchez et al. [16] in a fed-bath regime in outdoor conditions have achieved nearly $4 \mathrm{~kg} \mathrm{~m}^{-3}$ of biomass concentration and a maximum specific growth rate of $0.80 \mathrm{day}^{-1}$ in a $60 \mathrm{~L}$ bubble column PBR after 15 days [16]. The study of Sánchez et al. [16] have suggested that for achieving higher biomass concentration using bubble column PBR it is needed to control the main culture parameters as temperature, $\mathrm{pH}$ and nutrient supplementation, even in outdoor conditions.

The $\mathrm{OD}_{680} / \mathrm{OD}_{550}$ ratio for the experiments is shown in Figure 3. The ratio between the OD at $680 \mathrm{~nm}\left(\mathrm{OD}_{680}\right)$ and $550 \mathrm{~nm}\left(\mathrm{OD}_{550}\right)$ can be used as an indicator of chlorophyll content per cell, allowing a controlled parameter for cells bleaching due to photoinhibition. This ratio was maintained at around 1.03 during the entire cultivation period, seemingly unaffected by variations in natural light intensity, contrary to observations in other works.

Light intensity was measured during the entire cultivation period, the PAR value and its standard deviation was $870 \pm 372 \mu \mathrm{mol}$ photons $\mathrm{m}^{-2} \mathrm{~s}^{-1}$ (Figure 4a). The study conducted by Miron et al. [35] has revealed similar results with a PAR value of $900 \mu \mathrm{mol}$ photons $\mathrm{m}^{-2} \mathrm{~s}^{-1}$ in a culture of P. tricornutum carried out in a bubble column PBR that have attained a biomass concentration of approximately $1 \mathrm{~kg} \mathrm{~m}^{-3}$ and a biomass productivity of $0.3 \mathrm{~kg} \mathrm{~m}^{-3} \mathrm{~d}^{-1}$.

During the cultivation period, there was a large variation in natural light intensity. Besides this variability, the culture appeared to be unchanged by this factor. The apparent culture insensibility can be explained by the fluid flow in the bubble column PBR, where the cells did not experiment an extended period of darkness because of the high frequency of radial dark-light movement, from the central darker core of the reactor to the illuminated border of the column [16,30]. Other studies have suggested that $P$. tricornutum's growth does not change in accordance with light intensity [31]. In fact, studies of productivity in P. tricornutum cultures exposed to different light intensities, from $100 \mu \mathrm{mol}$ photons $\mathrm{m}^{-2} \mathrm{~s}^{-1}$ onwards produces light saturation regardless of constant productivity which seems to be independent of increasing intensities $[31,36,37]$. However, cultures with limited light intensities are generally expected to increase the biomass productivity upon the enhancement of light intensities [38]. This fact can be explained by the photoinhibition process that occurs in cells under light intensities above $100 \mu \mathrm{mol}$ photons $\mathrm{m}^{-2} \mathrm{~s}^{-1}$. In addition, when the molecular machinery becomes inhibited no further inhibition occurs regardless the increase in irradiance [39].

Concerning the dissolved oxygen generated by photosynthesis during the cultivation period, it was observed a maximum of $9.38 \pm 0.16 \mathrm{mg} \mathrm{L}^{-1}$ at day 8 of cultivation, period in which the culture 
also reached the highest areal productivity and growth rate (Figure $4 b$ ). The oxygen saturation ranged from $97.88 \pm 4.50 \%$ to $125.90 \pm 2.42 \%$ (Figure $4 \mathrm{~b}$ ). The oxygen generated by photosynthesis during culture in bubble column PBR is generally freely removed because of the hydrodynamics and the good gas-liquid mass transfer characteristics of this type of reactors [40], hence the oxygen concentration does not exceed $126 \%$ of air saturation. On the other hand, similar results were achieved by other studies [41] using a membrane-based localized oxygen remover able to maintain dissolved oxygen at $120 \%, 32 \%$ lower than the conventional bubble column PBR. However, in this study no deoxygenation equipment was used to maintain the oxygen saturation below $126 \%$.

High concentrations of dissolved oxygen in the culture can suppress the photosynthesis. Moreover, the combination of a high dissolved oxygen level and intense natural irradiance can lead to biomass damage by photo-oxidation [32]. Conventional tubular PBR usually enable oxygen accumulation above $400 \%$ [32], which leads to photo-oxidation and oxygen inhibition. On the other hand, in column bioreactors usually these processes do not occur because of the large diameter of the vertical column and the high gas-liquid mass transfer rates [16].

\subsection{Total Lipid Measurement}

After the harvesting and lyophilizing processes, the total lipids were extracted and quantified. Lipid extractions were carried out with Soxhlet extraction using hexane $\left(60^{\circ} \mathrm{C}\right)$ and the Bligh and Dyer method at room temperature and pressure. Table 1 shows crude lipid yields for the different extraction methods. As expected, the Bligh and Dyer method extracted a relatively large amount of lipids $(9.08 \pm 0.38 \mathrm{wt} \%)$ in $1 \mathrm{~h}$, whereas Soxhlet extraction with hexane yielded only $3.99 \pm 0.69 \mathrm{wt} \%$ lipids after $24 \mathrm{~h}$, without previous cell disruption.

Table 1. Total lipids of P. tricornutum determined by the Soxhlet extraction method using hexane as solvent and by the Bligh and Dyer method, using methanol and chloroform as co-solvents.

\begin{tabular}{ccc}
\hline \multirow{2}{*}{ Parameter } & \multicolumn{2}{c}{ Extracting Solvent } \\
\cline { 2 - 3 } & Hexane & Methanol/Chloroform \\
\hline Total lipids $\left(\mathrm{wt}_{\mathrm{o}}\right)$ & $3.99 \pm 0.69$ & $9.08 \pm 0.38$ \\
Lipids productivity $\left(\mathrm{g} \mathrm{m}^{-2} \mathrm{~d}^{-1}\right)$ & $10.37 \pm 1.80$ & $23.61 \pm 0.99$ \\
\hline
\end{tabular}

Lipid productivity was calculated as the product of biomass productivity with lipid content. Lipid productivity obtained from hexane lipid extraction and the Bligh and Dyer method was $10.37 \mathrm{~g} \mathrm{~m}^{-2} \mathrm{~d}^{-1}$ and $23.61 \mathrm{~g} \mathrm{~m}^{-2} \mathrm{~d}^{-1}$, respectively. Based on these results it can be concluded that the highest yield efficiency was achieved with the Bligh and Dyer method. Similar efficiency with hexane and methanol/chloroform solvent-based lipid extractions was observed in other studies [42,43]. Previous studies have estimated lipid content in P. tricornutum between $5.4 \mathrm{wt} \%$ and $10.7 \mathrm{wt} \%$ after extractions carried out with chloroform/methanol solvents [44]. Chauton et al. [10] have also found a chloroform -extractable lipids content of $10 \%$ of biomass dry weight in P. tricornutum cultivated in a fed batch-culture regime. Wawrik and Harriman [45] have estimated $9.4 \mathrm{wt} \%$ of cellular lipid contents at the stationary phase for $P$. tricornutum cultivated indoor in batch regime.

Nevertheless, the lipid content in P. tricornutum was not as high as reported previously [46]. Lipid yield can vary as a result of light intensity, while exposed to higher light intensities the lipid content is lower than the lowest light intensity [31]. The cellular content of lipids also differs as a result of culture phases. Lower lipid content can be found in actively growing cells rather than in those in the stationary phase [10]. Indeed, in this study the cells were harvested when the culture just reached the stationary phase. Another possibility to improve lipid content in a microalgae culture is to consider the fed-batch cultivation system for providing a continuous production of high-value compounds and nitrogen starvation conditions. Naturally, this end point can be explained because the cells, cultivated under stressed conditions, usually respond by stimulating the production of energy reserves [47]. 
Despite the fact that the Bligh and Dyer method is normally used as a benchmark for quantifying the total lipid content from microalgae, it is not environmentally and economically feasible at an industrial scale, due to large quantities of hazardous waste solvents generated by the process. For this reason, some studies have looked for new or improved methods for enhancing the microalgae lipid extraction using hexane [42,48]. Hexane is an organic, solvent mostly used in large scale lipid extraction because of its cost-effectiveness and recyclability. It is less toxic than chloroform and more environmentally friendly for biodiesel production $[49,50]$. Although hexane has been reported to be less efficient than chloroform-based methods for microalgal lipid extractions, some studies have demonstrated that using hot compressed hexane could enhance its otherwise low efficiency [42]. Furthermore, other studies [48] have suggested that dividing the hexane/hydroalcoholic phase into two steps for improving lipid recovery would result in a reduction of toxic solvents and subsequently, reducing the total amount of solvents used.

The rapidly growing young cells generally lead to a lower content of storage lipids and more proteins than cells cultured at lower specific growth rates [51]. The variance observed in the total lipids quantification of microalgae biomass, when comparing different studies and culture conditions, can be explained by the large variability of environmental factors that affect the growth rate and productivities [52]. Also, lipid content is strongly influenced by environmental effects, such as nitrogen limitations, temperature and irradiance in P. tricornutum cultures [47].

\subsection{Fatty Acids Compositions}

Lipids are important components for energy storage for most organisms, including microalgae. The diatom P. tricornutum produces some fatty acids that are potentially significant raw material for biodiesel production and/or high-value compounds. The composition and relative abundance of each microalgae fatty acid was estimated based on the GC area signals (\% area per sample) for the corresponding FAME as shown in Table 2 (see also Figure S1 and Table S1 in the Supplementary Materials). The fatty acid profile obtained by gas chromatography analysis of P. tricornutum's lipids showed that the alga contained more than 15 different fatty acids, of which five represent more than $8 \%$ of the total fatty acid content.

Table 2. Fatty acid compositional profiles of Phaeodactylum tricornutum.

\begin{tabular}{cccc}
\hline Fatty Acids & Chain & Mass Fraction (\%) & FAME Yield (wt \%) ${ }^{\mathbf{1}}$ \\
\hline Undecanoic acid & C11:0 & 0.07 & 0.01 \\
Decanoic acid & C12:0 & 8.94 & 0.81 \\
Pentadecanoic acid & C15:0 & 15.82 & 1.44 \\
Pentadecenoic acid & C15:1 & 13.43 & 1.22 \\
Palmitoleic acid & C16:1 & 4.89 & 0.44 \\
Heptadecanoic acid & C17:0 & 12.06 & 1.10 \\
Heptadecenoic acid & C17:1 & 1.12 & 0.10 \\
Stearic acid & C18:0 & 3.18 & 0.29 \\
Oleic acid & C18:1 & 2.47 & 0.22 \\
Linoleic acid & C18:2 & 0.67 & 0.06 \\
Henicosanoic acid & C21:0 & 2.27 & 0.21 \\
Eicosadienoic acid & C20:2 & 0.51 & 0.05 \\
Eicosatrienoic acid & C20:3 & 29.69 & 2.70 \\
Arachidonic acid & C24:4 & 0.54 & 0.05 \\
Docosadienoic acid & C22:2 & 0.61 & 0.06 \\
Not identified & - & 3.75 & 0.34 \\
SFA & - & 42.34 & 3.84 \\
MUFA & - & 21.91 & 1.99 \\
PUFA & - & 31.41 & 2.85 \\
\hline
\end{tabular}

${ }^{1}$ Each FAME percentage in biomass calculated by the equation: FAME yield $(w t \%)=$ Crude lipid yield $(w t \%) \times$ FAME content $(\%) / 100$. 
Analysis of FAME profile plays a crucial role when determining fuel properties. FAME consists mainly of saturated and unsaturated carbon chain lengths from C11 to C24. The most important fraction was the eicosatrienoic acid (C20:3), with a relative abundance of $29.69 \%$ or $2.70 \mathrm{wt} \%$ of the total microalgae dry biomass. In particular, the occurrence of C16-C18 fatty acids is considered as a good composition for biodiesel production [53]. P. tricornutum samples showed $24.39 \%$ of C16-C18 fatty acids, which can provide the most suitable relation between cold flow properties and oxidative stability [53]. Concerning the presence of saturated fatty acids (SFA) and monounsaturated fatty acids (MUFA), the samples showed a proportion of $42.34 \%$ (3.84 wt \%) and $21.91 \%(1.99 \mathrm{wt} \%)$ respectively (Table 2$)$. Other studies [2] have shown a higher proportion of these fatty acids (SFA-50.16\% and MUFA-48.79\%), but this enhancement is explained by the use of different gas-liquid ratios. Yet, the relation between SFA and MUFA is similar to the values reported in this work. These findings suggest that biodiesel could achieve high cetane numbers and low iodine values, meeting European (EN 14214) and US (ASTM D6751) standard requirements [54,55].

The FAME profile showed that $P$. tricornutum contained considerable amounts of PUFA $(31.41 \%$ or $2.85 \mathrm{wt} \%$ ) (Table 2). P. tricornutum's PUFA production has been reported in outdoor cultures, and findings suggested that under nutrient-replete conditions the amount of PUFA can reach $60 \%$ [56]. However, as this study was conducted outdoors under nutrient replete conditions, the amounts of PUFA were lower than other studies, which could be explained by differences in temperature and light conditions. The European standard for biodiesel (EN 14214) requires less than 1\% of highly polyunsaturated fatty acids ( $\geq 4$ double bonds), which could influence fuel properties of the resulting biodiesel. Although the high concentration of PUFA at $P$. tricornutum's FAME analyses showed low values $(0.54 \%)$ for arachidonic acid (C24:4), a highly polyunsaturated fatty acid present in this microalgae oil. The total amount of PUFA can be a problem when producing biodiesel that fulfills the standard criteria.

Considering FAME yields, SFA, MUFA and PUFA corresponded to $3.84 \mathrm{wt} \%, 1.99 \mathrm{wt} \%$ and $2.85 \mathrm{wt} \%$ of the total dried biomass (Table 2). It is known that the quality of fatty acids changes depending on the environmental culture conditions and the age of the culture. Yodsuwan et al. [57] have found that cultures with low nitrogen concentration result in higher levels of saturated fatty acids than those cultivated with higher nitrogen concentration in the exponential growth phase. Alonso et al. [58] have studied in continuous cultures the influence of age and nitrogen concentration in fatty acids distribution among different lipid classes of P. tricornutum. These authors have concluded that although age shows almost no influence on fatty acid content, both the saturated and monounsaturated fatty acids content increases when nitrogen concentration decreases. Oleic acid (C18:1) usually increases in older cultures of P. tricornutum at their late stationary phases [57]. Oleic acid is known to play an important role in the lipid metabolism of $P$. tricornutum as a precursor of PUFA during the exponential growth phase [11]. In fact, in this study, high contents of PUFA were found in the culture, harvested in the early stationary phase, when oleic content was lower and PUFA higher. Probably, in a later stationary stage of this culture it would be possible to find opposite results.

In this study, EPA, a common fatty acid present in P. tricornutum biomass, was not observed. The possible reason for absence of this fatty acid can be the fact that cell harvest was done immediately in the moment when the early stationary phase started. EPA has been described as an important constituent of cell membranes and photosynthetic membrane lipids [31]. Hence, in this culture phase the cells were just finishing their replication process and using all the EPA produced in their metabolism. Also, Yongmanitchai and Ward [59] have reported that the optimum temperature conditions for producing EPA is in the range of $21.5-23.0^{\circ} \mathrm{C}$ and $\mathrm{pH}$ at 7.6. In this work the temperature was lower, from 17 to $21^{\circ} \mathrm{C}$, and $\mathrm{pH}$ varied from 7 to 9 , outside optimal conditions. Furthermore, some authors have reported that microalgae cultured outdoors, facing more environmental challenges such as irradiance, temperature variation and nutritional stresses, showed variations within their lipid composition and can produce energy-reservoir lipids instead of structural lipids $[47,60]$. Acién Fernández et al. [34] have presented a model for predicting EPA productivity from P. tricornutum 
cultures in Spain, taking into account the existence of photo-limitation and photoinhibition under outdoor conditions. These authors have concluded that biomass productivity is limited by low light availability (e.g., during winter), but EPA content is higher under optimal light availability (e.g., during summer), especially when biomass productivity is higher. This could be caused by photoinhibition.

\section{Conclusions}

This study analyzed the growth and lipid productivity of $P$. tricornutum, cultivated in outdoor bubble columns PBR under natural conditions in Chile, and its potential for biodiesel production. Results showed a final dry weight biomass concentration of $0.96 \mathrm{~kg} \mathrm{~m}^{-3}$, with a maximum volumetric productivity of $0.13 \mathrm{~kg} \mathrm{~m}^{-3} \mathrm{~d}^{-1}$ and total lipid content of $9.08 \mathrm{wt} \%$. FAME profile was analyzed and the composition of these fatty acids showed a proportion of $42.34 \%$ of SFA, $21.91 \%$ of MUFA and $31.41 \%$ of PUFA. This profile meets the requirements of international biodiesel standards, showing that $P$. tricornutum can be a good alternative for biodiesel production. However, it is necessary to develop further studies to evaluate the lipid content and productivity of this microalga at different geographical locations, considering different climate and stress inducing conditions, to effectively determine its potential for biodiesel production and other applications, since the fatty acids profile and biochemical components change under diverse farming environments.

Supplementary Materials: The following are available online at www.mdpi.com/1996-1073/11/1/54/s1, Figure S1: Gas Chromatography peaks from P. tricornutum Fatty Acid Methyl Esters. Table S1: Total Fatty Acid Methyl Esters obtained from P. tricornutum Gas Chromatography transesterificated oil.

Acknowledgments: Authors acknowledge “Convenio de Desempeño Ciencia, Tecnología e Innovación para la Bioeconomía", from Chilean government, for their support throughout this work. Authors also acknowledge the financial support from PFRH Petrobrás (Brazil) and European Commission (through Erasmus Mundus Program) post graduate research scholarship. Authors thank the financial support of POCI-01-0145-FEDER-006939 (Laboratory for Process Engineering, Environment, Biotechnology and Energy-LEPABE) funded by FEDER through COMPETE2020-POCI and by national funds through FCT. Authors also thank FCT for project FCT UID/EQU/00305/2013 (Center for Innovation in Engineering and Industrial Technology-CIETI) and for their support through provision of the research grants IF/01093/2014 and SFRH/BPD/112003/2015. Authors also acknowledge Andrés Agurto for the grammatical revisions of the manuscript.

Author Contributions: Monique Branco-Vieira, Sergio San Martin and Cristian Agurto conceived, designed and performed the experiments; Monique Branco-Vieira and Sergio San Martin analyzed the data; Monique Branco-Vieira, Teresa Mata and António Martins wrote the paper under guidance of Nídia Caetano. Cristian Agurto, Nídia Caetano, Marcos Aurélio dos Santos, Marcos A. V. Freitas contributed with analysis tools and characterizations. Nídia Caetano revised the paper.

Conflicts of Interest: The authors declare no conflict of interest.

\section{References}

1. Maranduba, H.L.; Robra, S.; Nascimento, I.A.; da Cruz, R.S.; Rodrigues, L.B.; de Almeida Neto, J.A. Improving the energy balance of microalgae biodiesel: Synergy with an autonomous sugarcane ethanol distillery. Energy 2016, 115, 888-895. [CrossRef]

2. Song, M.; Pei, H.; Hu, W.; Han, F.; Ji, Y.; Ma, G.; Han, L. Growth and lipid accumulation properties of microalgal Phaeodactylum tricornutum under different gas liquid ratios. Bioresour. Technol. 2014, 165, 31-37. [CrossRef] [PubMed]

3. Chisti, Y. Biodiesel from microalgae. Biotechnol. Adv. 2007, 25, 294-306. [CrossRef] [PubMed]

4. Mata, T.M.; Martins, A.A.; Caetano, N.S. Microalgae processing for biodiesel production. In Advances in Biodiesel Production; Melero, J.A., Luque, R., Eds.; Woodhead Publishing Series in Energy No. 39, Ch. 9; Woodhead Publishing: Cambridge, UK, 2012; pp. 204-231, ISBN 9780857091178.

5. Pinedo, J.; Prieto, C.V.G.; D'Alessandro, A.A.; Ibáñez, R.; Tonelli, S.; Díaz, M.S.; Irabien, Á. Microalgae biorefinery alternatives and hazard evaluation. Chem. Eng. Res. Des. 2016, 107, 117-125. [CrossRef]

6. Mata, T.M.; Mendes, A.M.; Caetano, N.S.; Martins, A.A. Sustainability and economic evaluation of microalgae grown in brewery wastewater. Bioresour. Technol. 2014, 168, 151-158. [CrossRef] [PubMed] 
7. Haro, P.; Sáez, K.; Gómez, P.I. Physiological plasticity of a Chilean strain of the diatom Phaeodactylum tricornutum: The effect of culture conditions on the quantity and quality of lipid production. J. Appl. Phycol. 2017, 29, 2771-2782. [CrossRef]

8. Benavides, A.M.S.; Torzillo, G.; Kopecký, J.; Masojídek, J. Productivity and biochemical composition of Phaeodactylum tricornutum (Bacillariophyceae) cultures grown outdoors in tubular photobioreactors and open ponds. Biomass Bioenergy 2013, 54, 115-122. [CrossRef]

9. Wishkerman, A.; Arad, S. Production of silver nanoparticles by the diatom Phaeodactylum tricornutum. In Silicon; Tiginyanu, I.M., Ed.; Elsevier Academic Press: Amsterdam, The Netherlands, 2017; Volume 4, p. 102480W.

10. Chauton, M.S.; Olsen, Y.; Vadstein, O. Biomass production from the microalga Phaeodactylum tricornutum: Nutrient stress and chemical composition in exponential fed-batch cultures. Biomass Bioenergy 2013, 58, 87-94. [CrossRef]

11. Hamilton, M.L.; Haslam, R.P.; Napier, J.A.; Sayanova, O. Metabolic engineering of Phaeodactylum tricornutum for the enhanced accumulation of omega-3 long chain polyunsaturated fatty acids. Metab. Eng. 2014, 22, 3-9. [CrossRef] [PubMed]

12. Gao, B.; Chen, A.; Zhang, W.; Li, A.; Zhang, C. Co-production of lipids, eicosapentaenoic acid, fucoxanthin, and chrysolaminarin by Phaeodactylum tricornutum cultured in a flat-plate photobioreactor under varying nitrogen conditions. J. Ocean Univ. China 2017, 16, 916-924. [CrossRef]

13. Pérez, E.B.; Pina, I.C.; Rodríguez, L.P. Kinetic model for growth of Phaeodactylum tricornutum in intensive culture photobioreactor. Biochem. Eng. J. 2008, 40, 520-525. [CrossRef]

14. Acién, F.G.; Molina, E.; Reis, A.; Torzillo, G.; Zittelli, G.C.; Sepúlveda, C.; Masojídek, J. Photobioreactors for the production of microalgae. Rev. Environ. Sci. Biotechnol. 2013, 12, 131-151. [CrossRef]

15. Huang, Q.; Jiang, F.; Wang, L.; Yang, C. Design of Photobioreactors for mass cultivation of photosynthetic organisms. Engineering 2017, 3, 318-329. [CrossRef]

16. Mirón, A.S.; García, M.-C.C.; Camacho, F.G.; Grima, E.M.; Chisti, Y. Growth and biochemical characterization of microalgal biomass produced in bubble column and airlift photobioreactors: Studies in fed-batch culture. Enzyme Microb. Technol. 2002, 31, 1015-1023. [CrossRef]

17. Zhu, L. The combined production of ethanol and biogas from microalgal residuals to sustain microalgal biodiesel: A theoretical evaluation. Biofuels Bioprod. Biorefin. 2014, 8, 7-15. [CrossRef]

18. Viruela, A.; Murgui, M.; Gómez-Gil, T.; Durán, F.; Robles, Á.; Ruano, M.V.; Ferrer, J.; Seco, A. Water resource recovery by means of microalgae cultivation in outdoor photobioreactors using the effluent from an anaerobic membrane bioreactor fed with pre-treated sewage. Bioresour. Technol. 2016, 218, 447-454. [CrossRef] [PubMed]

19. Pérez, L.; Salgueiro, J.L.; González, J.; Parralejo, A.I.; Maceiras, R.; Cancela, Á. Scaled up from indoor to outdoor cultures of Chaetoceros gracilis and Skeletonema costatum microalgae for biomass and oil production. Biochem. Eng. J. 2017, 127, 180-187. [CrossRef]

20. Schoepp, N.G.; Stewart, R.L.; Sun, V.; Quigley, A.J.; Mendola, D.; Mayfield, S.P.; Burkart, M.D. System and method for research-scale outdoor production of microalgae and cyanobacteria. Bioresour. Technol. 2014, 166, 273-281. [CrossRef] [PubMed]

21. Guihéneuf, F.; Leu, S.; Zarka, A.; Khozin-Goldberg, I.; Khalilov, I.; Boussiba, S. Cloning and molecular characterization of a novel acyl-CoA:diacylglycerol acyltransferase 1-like gene (PtDGAT1) from the diatom Phaeodactylum tricornutum. FEBS J. 2011, 278, 3651-3666. [CrossRef] [PubMed]

22. Fernández, F.G.A.; Pérez, J.A.S.; Sevilla, J.M.F.; Camacho, F.G.; Grima, E.M. Modeling of eicosapentaenoic acid (EPA) production from Phaeodactylum tricornutum cultures in tubular photobioreactors. Effects of dilution rate, tube diameter, and solar irradiance. Biotechnol. Bioeng. 2000, 68, 173-183. [CrossRef]

23. Walne, P. Studies on the Food Value of Nineteen Genera of Algae to Juvenile Bivalves of the Genera Ostrea, Crassostrea, Mercenaria, and Mytilis; Fishery Investigations, Series 2; H.M. Stationery Office: London, UK, 1970; Volume 26, pp. 1-62.

24. Guillard, R.R.L.; Ryther, J.H. Studies of marine planktonic diatoms. I. Cyclotella nana Hustedt, and Detonula confervacea (cleve) Gran. Can. J. Microbiol. 1962, 8, 229-239. [CrossRef] [PubMed]

25. Griffiths, M.J.; Garcin, C.; van Hille, R.P.; Harrison, S.T.L. Interference by pigment in the estimation of microalgal biomass concentration by optical density. J. Microbiol. Methods 2011, 85, 119-123. [CrossRef] [PubMed] 
26. Kliphuis, A.M.J.; de Winter, L.; Vejrazka, C.; Martens, D.E.; Janssen, M.; Wijffels, R.H. Photosynthetic efficiency of Chlorella sorokiniana in a turbulently mixed short light-path photobioreactor. Biotechnol. Prog. 2010, 26, 687-696. [CrossRef] [PubMed]

27. Bligh, E.G.; Dyer, W.J. A rapid method of total lipid extraction and purification. Can. J. Biochem. Physiol. 1959, 37, 911-917. [CrossRef] [PubMed]

28. Mata, T.M.; Martins, A.; Oliveira, O.; Oliveira, S.; Mendes, A.M.; Nídia, C. Lipid content and productivity of Arthrospira Platensis and Chlorella Vulgaris under salinity stress and mixotrophic growth conditions. Chem. Eng. Trans. 2016, 49, 187-192. [CrossRef]

29. Mirón, A.S.; Gómez, A.C.; Camacho, F.G.; Grima, E.M.; Chisti, Y. Comparative evaluation of compact photobioreactors for large-scale monoculture of microalgae. Prog. Ind. Microbiol. 1999, 35, 249-270.

30. López-Rosales, L.; García-Camacho, F.; Sánchez-Mirón, A.; Martín Beato, E.; Chisti, Y.; Grima, E.M. Pilotscale bubble column photobioreactor culture of a marine dinoflagellate microalga illuminated with light emission diodes. Bioresour. Technol. 2016, 216, 845-855. [CrossRef] [PubMed]

31. Remmers, I.M.; Martens, D.E.; Wijffels, R.H.; Lamers, P.P. Dynamics of triacylglycerol and EPA production in Phaeodactylum tricornutum under nitrogen starvation at different light intensities. PLoS ONE 2017, 12, e0175630. [CrossRef] [PubMed]

32. Molina, E.; Fernández, J.; Acién, F.G.; Chisti, Y. Tubular photobioreactor design for algal cultures. J. Biotechnol. 2001, 92, 113-131. [CrossRef]

33. Hall, D.O.; Fernández, F.G.A.; Guerrero, E.C.; Rao, K.K.; Grima, E.M. Outdoor helical tubular photobioreactors for microalgal production: Modeling of fluid-dynamics and mass transfer and assessment of biomass productivity. Biotechnol. Bioeng. 2003, 82, 62-73. [CrossRef] [PubMed]

34. Sánchez, J.L.G.; Berenguel, M.; Rodríguez, F.; Sevilla, J.M.F.; Alias, C.B.; Fernández, F.G.A. Minimization of carbon losses in pilot-scale outdoor photobioreactors by model-based predictive control. Biotechnol. Bioeng. 2003, 84, 533-543. [CrossRef] [PubMed]

35. Mirón, A.S.; García, M.C.C.; Gómez, A.C.; Camacho, F.G.; Grima, E.M.; Chisti, Y. Shear stress tolerance and biochemical characterization of Phaeodactylum tricornutum in quasi steady-state continuous culture in outdoor photobioreactors. Biochem. Eng. J. 2003, 16, 287-297. [CrossRef]

36. Fernández, F.A.; Hall, D.O.; Guerrero, E.C.; Rao, K.K.; Grima, E.M. Outdoor production of Phaeodactylum tricornutum biomass in a helical reactor. J. Biotechnol. 2003, 103, 137-152. [CrossRef]

37. Geider, R.J.; Osborne, B.A.; Raven, J.A. Light dependence of growth and photosynthesis in Phaeodactylum tricornutum (Bacillariophyceae). J. Phycol. 2004, 21, 609-619. [CrossRef]

38. Breuer, G.; Lamers, P.P.; Martens, D.E.; Draaisma, R.B.; Wijffels, R.H. Effect of light intensity, pH, and temperature on triacylglycerol (TAG) accumulation induced by nitrogen starvation in Scenedesmus obliquus. Bioresour. Technol. 2013, 143, 1-9. [CrossRef] [PubMed]

39. Dillschneider, R.; Steinweg, C.; Rosello-Sastre, R.; Posten, C. Biofuels from microalgae: Photoconversion efficiency during lipid accumulation. Bioresour. Technol. 2013, 142, 647-654. [CrossRef] [PubMed]

40. Manjrekar, O.N.; Sun, Y.; He, L.; Tang, Y.J.; Dudukovic, M.P. Hydrodynamics and mass transfer coefficients in a bubble column photo-bioreactor. Chem. Eng. Sci. 2017, 168, 55-66. [CrossRef]

41. Peng, L.; Zhang, Z.; Cheng, P.; Wang, Z.; Lan, C.Q. Cultivation of Neochloris oleoabundans in bubble column photobioreactor with or without localized deoxygenation. Bioresour. Technol. 2016, 206, 255-263. [CrossRef] [PubMed]

42. Shin, H.-Y.; Ryu, J.-H.; Bae, S.-Y.; Crofcheck, C.; Crocker, M. Lipid extraction from Scenedesmus sp. microalgae for biodiesel production using hot compressed hexane. Fuel 2014, 130, 66-69. [CrossRef]

43. Ryckebosch, E.; Bruneel, C.; Termote-Verhalle, R.; Muylaert, K.; Foubert, I. Influence of extraction solvent system on extractability of lipid components from different microalgae species. Algal Res. 2014, 3, $36-43$. [CrossRef]

44. Siron, R.; Giusti, G.; Berland, B. Changes in the fatty acid composition of Phaeodactylum tricornutum and Dunaliella Tertiolecta during growth and under phosphorus deficiency. Mar. Ecol. Prog. Ser. 1989, 55, 95-100. [CrossRef]

45. Wawrik, B.; Harriman, B.H. Rapid, colorimetric quantification of lipid from algal cultures. J. Microbiol. Methods 2010, 80, 262-266. [CrossRef] [PubMed]

46. Mata, T.M.; Martins, A.A.; Caetano, N.S. Microalgae for biodiesel production and other applications: A review. Renew. Sustain. Energy Rev. 2010, 14, 217-232. [CrossRef] 
47. Santos-Ballardo, D.U.; Rendón-Unceta, M.D.C.; Rossi, S.; Vázquez-Gómez, R.; Hernández-Verdugo, S.; Valdez-Ortiz, A. Effects of outdoor cultures on the growth and lipid production of Phaeodactylum tricornutum using closed photobioreactors. World J. Microbiol. Biotechnol. 2016, 32, 128-138. [CrossRef] [PubMed]

48. Fajardo, A.R.; Cerdán, L.E.; Medina, A.R.; Fernández, F.G.A.; Moreno, P.A.G.; Grima, E.M. Lipid extraction from the microalga Phaeodactylum tricornutum. Eur. J. Lipid Sci. Technol. 2007, 109, 120-126. [CrossRef]

49. Grima, E.M.; Medina, A.R.; Giménez, A.G.; Pérez, J.A.S.; Camacho, F.G.; Sánchez, J.L.G. Comparison between extraction of lipids and fatty acids from microalgal biomass. J. Am. Oil Chem. Soc. 1994, 71, 955-959. [CrossRef]

50. Halim, R.; Gladman, B.; Danquah, M.K.; Webley, P.A. Oil extraction from microalgae for biodiesel production. Bioresour. Technol. 2011, 102, 178-185. [CrossRef] [PubMed]

51. Kaixian, Q.; Borowitzka, M.A. Light and nitrogen deficiency effects on the growth and composition of Phaeodactylurn tricornuturn. Appl. Biochem. Biotechnol. 1993, 38, 93-103. [CrossRef]

52. Schreiber, C.; Behrendt, D.; Huber, G.; Pfaff, C.; Widzgowski, J.; Ackermann, B.; Müller, A.; Zachleder, V.; Moudříková, Š.; Mojzeš, P.; et al. Growth of algal biomass in laboratory and in large-scale algal photobioreactors in the temperate climate of western Germany. Bioresour. Technol. 2017, 234, 140-149. [CrossRef] [PubMed]

53. Knothe, G. Improving biodiesel fuel properties by modifying fatty ester composition. Energy Environ. Sci. 2009, 2, 759. [CrossRef]

54. Hoekman, S.K.; Broch, A.; Robbins, C.; Ceniceros, E.; Natarajan, M. Review of biodiesel composition, properties, and specifications. Renew. Sustain. Energy Rev. 2012, 16, 143-169. [CrossRef]

55. Refaat, A.A. Correlation between the chemical structure of biodiesel and its physical properties. Int. J. Environ. Sci. Technol. 2009, 6, 677-694. [CrossRef]

56. Rodolfi, L.; Biondi, N.; Guccione, A.; Bassi, N.; D'Ottavio, M.; Arganaraz, G.; Tredici, M.R. Oil and eicosapentaenoic acid production by the diatom Phaeodactylum tricornutum cultivated outdoors in Green Wall Panel (GWP ${ }^{\circledR}$ ) reactors. Biotechnol. Bioeng. 2017, 114, 2204-2210. [CrossRef] [PubMed]

57. Yodsuwan, N.; Sawayama, S.; Sirisansaneeyakul, S. Effect of nitrogen concentration on growth, lipid production and fatty acid profiles of the marine diatom Phaeodactylum tricornutum. Agric. Nat. Resour. 2017, 51, 190-197. [CrossRef]

58. Alonso, D.L.; Belarbi, E.H.; Fernández-Sevilla, J.M.; Rodríguez-Ruiz, J.; Grima, E.M. Acyl lipid composition variation related to culture age and nitrogen concentration in continuous culture of the microalga Phaeodactylum tricornutum. Phytochemistry 2000, 54, 461-471. [CrossRef]

59. Yongmanitchai, W.; Ward, O.P. Growth of and omega-3 fatty acid production by Phaeodactylum tricornutum under different culture conditions. Appl. Environ. Microbiol. 1991, 57, 419-425. [PubMed]

60. Nogueira, D.P.K.; Silva, A.F.; Araújo, O.Q.F.; Chaloub, R.M. Impact of temperature and light intensity on triacylglycerol accumulation in marine microalgae. Biomass Bioenergy 2015, 72, 280-287. [CrossRef] 